\title{
Diagnostic accuracy of noncompacted-to-compacted wall ratio criteria on CMRI for the diagnosis of left ventricular noncompaction
}

\author{
Deniz ALIS ${ }^{1}$ (D), Anil SAHIN² (D), Arda GULER² (D), Ozan ASMAKUTLU1 ${ }^{1}$ \\ 1 Radiology Clinic, Istanbul Mehmet Akif Ersoy Thoracic and Cardiovascular Surgery Research and Training Hospital, Halkall, Istanbul, Turkey \\ 2 Cardiology Clinic, Istanbul Mehmet Akif Ersoy Thoracic and Cardiovascular Surgery Research and Training Hospital, Halkalı, Istanbul, Turkey \\ Corresponding Author: Deniz ALIS \\ E-mail:drdenizalis@gmail.com
}

Submitted: $05.07 .2019 \quad$ Accepted: 01.09.2019

\begin{abstract}
Objectives: To investigate the diagnostic accuracy of the current criterion, noncompacted-to-compacted (NC/C) wall ratio $>2.3$ on cardiac magnetic resonance imaging (CMRI) for the diagnosis of left ventricular noncompaction (LVNC).

Materials and Methods: We retrospectively enrolled 37 patients as an LVNC group and a total of 97 participants with ischemic, hypertrophic, and dilated cardiomyopathy and healthy controls as a control group. The NC/C ratio was measured perpendicularly on short-axis cine images for segments 1-16 and four-chamber cine images for the apex during the end-diastole. The sensitivity, specificity, and diagnostic accuracy of $\mathrm{NC} / \mathrm{C}$ ratio $>2.3$ for the diagnosis of LVNC were calculated.

Results: LVNC patients comprised 24 males (64.8\%) and 13 females (35.2\%) with the mean age of $29.24 \pm 11.79$ years. The NC/C ratio $>2.3$ detected in all but one of the LVNC patients (97.3\%). On the other hand, the specificity of NC/C ratio $>2.3$ was $79.4 \%$ for the diagnosis of the LVNC patients. Using NC/C ratio $>2.66$ and $>2.8$ yielded $91.9 \%$ sensitivity and $97 \%$ specificity, and $81 \%$ sensitivity and $100 \%$ specificity, respectively.

Conclusion: NC/C ratio > 2.3 might lead to overdiagnosis of LVNC. We suggest using higher NC/C cut-off value in individuals without high clinical suspicion of LVNC.

Keywords: Accuracy, Cardiomyopathy, CMR, Cut-off, Noncompaction
\end{abstract}

\section{INTRODUCTION}

Left ventricular noncompaction (LVNC) is a type of cardiomyopathy with an estimated prevalence ranging from $0.014 \%$ to 0.17 , and up to $1.3 \%$ [1-3]. LVNC is currently recognized as "unclassified cardiomyopathy" by the European Society of Cardiology while the American Heart Association classified the disease as "distinct cardiomyopathy" [4,5]. Several genetic and environmental factors have been identified as the risk factors for LVNC development; however, the precise mechanisms leading to LVNC remains poorly understood [6-8]. The disease is principally delineated by increased endocardial trabeculations, deep intertrabecular recesses communicating with the left ventricular cavity, and thin compacted myocardium [9]. LVNC manifests with a heterogeneous clinical spectrum ranging from systemic thromboembolism, arrhythmia, and heart failure to asymptomatic course for a lifetime [10].

Echocardiography is a first-line imaging modality in case of LVNC suspicion whereas cardiac magnetic resonance imaging (CMRI) is being increasingly employed for the diagnosis of LVNC given to its higher spatial and contrast-resolution, multiplanar imaging capability, and higher inter-observer variability
$[9,11,12]$. Various diagnostic criteria have been proposed for the diagnosis of LVNC on CMRI. Petersen et al., introduced a practical semi-quantitative criterion, noncompacted-tocompacted $(\mathrm{NC} / \mathrm{C})$ myocardium threshold ratio $>2.3$ at enddiastole on CMRI for the diagnosis LVNC [12]. Despite it is being extensively used in daily practice owing to its practicality and high inter-observer variability, several authors have raised concerns regarding the reliability of Petersen's criteria $[13,14]$. Much of the debate has gathered around the specificity of the approach, and several authors claimed that using $\mathrm{NC} / \mathrm{C}>2.3$ might lead to overdiagnosis of LVNC $[13,14]$.

The aim of the study was twofold: (1) to test the diagnostic accuracy of the criterion, NC/C wall threshold ratio $>2.3$ on CMRI for the diagnosis of LNVC, and (2) to explore whether a refined cut-off value with higher diagnostic accuracy could be established on CMRI.

\section{MATERIALS and METHODS}

The Institutional Ethics Committee of Istanbul Mehmet Akif Ersoy Thoracic and Cardiovascular Surgery Research and

How to cite this article: Alis D, Sahin A, Guler A, Asmakutlu O. Diagnostic accuracy of noncompacted-to-compacted wall ratio criteria on CMRI for the diagnosis of left ventricular noncompaction. Marmara Med J 2019; 32: 124-129. doi: 10.5472/marumj.637581 
Training Hospital approved (registration number 2017-34) this retrospective study conducted between January 2018 and May 2019 and waived the need for informed consent for the investigation and presentation of deanonymized medical data. We retrospectively evaluated our picture and archive communicating system (PACS, ExtremePacs, Ankara/Turkey) to identify patients scheduled for CMRI examination on a provisional diagnosis of LVNC. The diagnosis of LVNC was established according to the recommendation of Jenni et al. [9] on echocardiographic imaging. To enhance the reliability of LVNC diagnosis, we have implemented several additional clinical and imaging criteria, and patients had to meet at least one of these criteria to be included in the final LVNC cohort: (1) having one first-degree relative with a diagnosis of LVNC, (2) having associated neuromuscular disorder, (3) having ventricular tachyarrhythmia detected on 24-hours Holter examination, (4) history of systemic thromboembolic events, and (5) appearance of distinct double layered ventricle composed of NC/C on CMRI [ 9, 10, 15,16]. We did not use the criterion introduced by Petersen et al. since the primary purpose of the current work was to test the diagnostic value of the criteria [12]. Exclusion criteria for LVNC cohort were: (1) having a diagnosis of coronary diseases, (2) having a diagnosis of other cardiomyopathies, and (3) having congenital heart disease. As control group, potential mimickers such as hypertrophic cardiomyopathy (HCM), dilated cardiomyopathy (DCM), and ischemic cardiomyopathy and healthy controls without any ischemic, valvular, autoimmune disease or known cardiomyopathy were included in the present work.

\section{CMRI acquisition}

All MRI studies were acquired with a $1.5 \mathrm{~T}$ scanner (Aera, Siemens Medical Systems, Enlargen/Germany). All CMRI acquisitions were performed using phased-array body coils. All of the sequences were acquired using prospective cardiac gating. Our CMRI protocol in the order of first to latest consisted of breath-hold black-axial blood fast spin-echo (SE), multiple breath-hold long-axis four-chamber, long axis two-chamber, and a 9-12 stack of short axes cine images breath-hold using balanced steady-state free precession imaging (SSFP). The parameters for SSFP cine images were: TR/TE $=3.8 / 1-3 \mathrm{~ms}$, slice thickness $=5 \mathrm{~mm}$ with $5 \mathrm{~mm}$ interslice gap, temporal resolution $=35 \mathrm{~m}$.

\section{Image Analysis}

The CMRI images of the patients were retrieved from our hospital picture archiving and communicating system (PACS, ExtremePacs system, Ankara/Turkey).

A single radiologist (D.A) with over four years of CMRI interpretation experience assessed all the CMRI images. First, the observer assessed the left ventricular functions by calculating ejection fraction (EF) using modified Simpson's method on short-axis cine images with the software (ARGUS, Siemens, Erlangen/Germany). The observer semi-automatically traced the endocardial and epicardial borders as demonstrated in several previous works $[9,11,12]$. The left ventricular myocardium divided into 17 segments as six regions at the basal level, six regions at the midventricular level, four regions at apical level, and apex according to the American Heart Association segmentation model for the left ventricle [17].

The NC/C myocardium was perpendicularly measured on short-axis cine images for segments 1-16 and measured on fourchamber cine images for segment 17 , as recommended in the previous works [15]. All measurements were performed at enddiastole using digital clippers. The segment, which the maximum ratio was achieved was determined, and the maximum $\mathrm{NC} / \mathrm{C}$ myocardium ratio was noted for each patient. The maximum ratios of $\mathrm{NC} / \mathrm{C}$ myocardium were separately calculated for segments 1-16 and segment 17. Figure 1 shows measurement of $\mathrm{NC} / \mathrm{C}$ ratio in a LVNC patient.

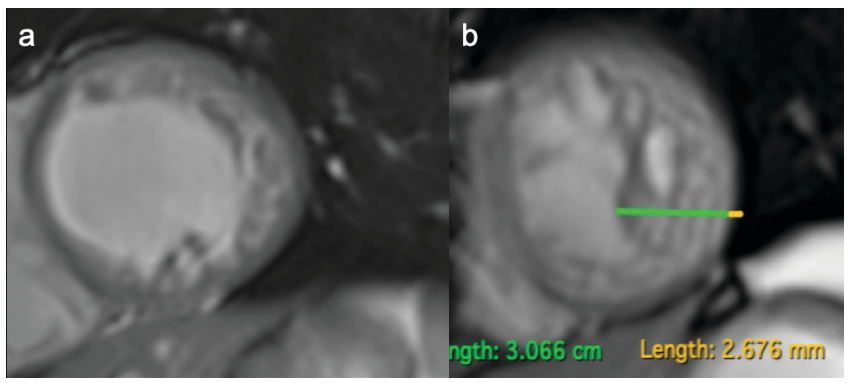

Figure 1. Short-axis cine images of a patient with myocardial noncompaction show deep trabecular recesses, double layer appearance in segment 7,8 (a) and 13,14,15 (b). The maximum $\mathrm{NC} / \mathrm{C}$ ratio was measured as 11,23 in segment 14 in this patient.

\section{Statistical analyses}

Statistical analyses were performed using the SPSS software version 21. The variables were investigated using KolmogorovSimirnov test to determine whether or not they were normally distributed. Descriptive analyses were presented using means and standard deviations for normally distributed variables and median and interquartile ranges for non-normally distributed variables. The Chi-square test was used to compare proportions of mitral regurgitation, and gender between two groups. Patients were classified using the cut-off value for NC/C ratio $>$ 2.3. LVNC patients with $\mathrm{NC} / \mathrm{C}>2.3$ were accepted as true positive (TP) cases, while LVNC patients with $\mathrm{NC} / \mathrm{C}<2.3$ were accepted as false negative (FN) cases. In control group, participants with $\mathrm{NC} / \mathrm{C}>2.3$ were accepted as false positive (FP), while participants with $\mathrm{NC} / \mathrm{C}<2.3$ were accepted as true negative (TN). The sensitivity was calculated as TP / (TP + FN), the specificity was calculated as $\mathrm{TN} /(\mathrm{TN}+\mathrm{FP})$, and diagnostic accuracy was calculated as $(\mathrm{TP}+\mathrm{TN}) /(\mathrm{TP}+\mathrm{TN}+\mathrm{FP}+\mathrm{FN})$. The segments with $\mathrm{NC} / \mathrm{C}$ ratio $>2.3$ in LVNC patients were demonstrated using visual graphs according to the American Heart Association segmentation model for the left ventricle. The proportion of segments with $\mathrm{NC} / \mathrm{C}$ wall ratio $>2.3$ in LVNC group and controls were compared using Man-Whitney- $U$ 
test. A P value of less than 0.05 was used to infer statistical significance.

\section{RESULTS}

Consecutive 37 patients with LVNC, 24 males (64.8\%) and 13 females $(35.2 \%)$, with a mean age of $29.24 \pm 11.79$ years were enrolled in the final study cohort. The control group consisted of 21 patients with ischemic cardiomyopathy, 21 patients with HCM, 38 healthy controls, and 17 patients with dilated cardiomyopathy. The mean age of LVNC patients, healthy controls, and DCM patients was comparable $(\mathrm{p}>0.05)$ while the mean age patients with ischemic cardiomyopathy and HCM exceeded the mean age of LVNC patients $(p<0.0001)$. The detailed CMRI findings of each group are listed in table I. Figure 2 shows the NC/C wall ratio of each group using violin plot graphs.

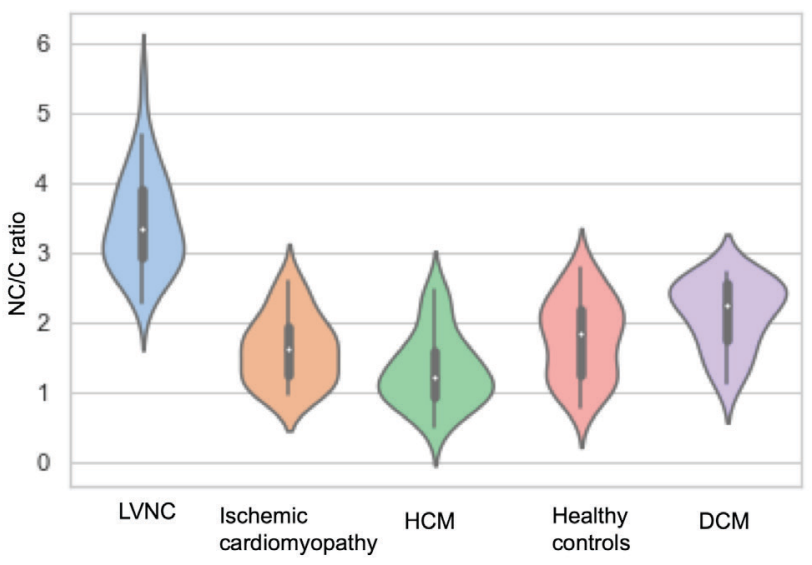

Figure 2. Violin-plot graph shows the NC/C ratio of each group

For the whole study cohort, a total of 56 patients had NC/C wall ratio $>2.3$. Among 56 patients, 8 patients had 1 segment (14.3\%), 16 had 2 segments (28.6\%), 13 had 3 segments $(23.2 \%), 7$ had 4 segments $(12.5 \%)$, and 12 had 5 segments or more $(18.4 \%)$ with $\mathrm{NC} / \mathrm{C}$ wall ratio $>2.3$. In LVNC patients, 36 patients had $\mathrm{NC} / \mathrm{C}$ wall ratio $>2.3$. In LVNC group, non of the patients had 1 segment with $\mathrm{NC} / \mathrm{C}$ wall ratio $>2.3$, while 5 patients had 2 segments (13.9\%), 12 had 3 segments (33.3\%), 7 had 4 segments (19.4\%), and 12 had 5 segments or more (33.4\%) with $\mathrm{NC/C}$ wall ratio $>2.3$. Notably, in control group, among 20 patients with $\mathrm{NC} / \mathrm{C}$ wall ratio $>2.3,8$ patients had 1 segment $(40 \%)$, 11 had 3 segments (55\%), and 1 had 3 segments (5\%) with $\mathrm{NC} / \mathrm{C}$ wall ratio $>2.3$. No patients in the control group had 4 or more segments with $\mathrm{NC} / \mathrm{C}$ wall ratio $>2.3$. The proportion of the segments with $\mathrm{NC} / \mathrm{C}$ wall ratio $>2.3$ in LVNC group was statistically higher compared with the control group $(\mathrm{p}<0.0001)$. Figure 3 shows the segments with NC/C ratio $>2.3$ for LVNC patients using a bull-eye graph.
Table I. CMRI findings of LVNC patients and control group and diagnostic metrices of different cut-off values for LVNC

\begin{tabular}{|c|c|c|c|c|c|}
\hline Variables & $\begin{array}{l}\text { LVNC } \\
(\mathrm{n}=37)\end{array}$ & $\begin{array}{l}\text { Ischemic } \\
\text { cardiom- } \\
\text { yopathy } \\
(\mathrm{n}=21)\end{array}$ & $\begin{array}{l}\mathrm{HCM} \\
(\mathrm{n}=21)\end{array}$ & $\begin{array}{l}\text { Healthy } \\
\text { controls } \\
(\mathrm{n}=38)\end{array}$ & $\begin{array}{l}\text { DCM } \\
(n=17)\end{array}$ \\
\hline Age (years) & $\begin{array}{l}29.24 \pm \\
11.79\end{array}$ & \begin{tabular}{|l}
$57.76 \pm$ \\
13.17 \\
\end{tabular} & \begin{tabular}{|l|}
$46.95 \pm$ \\
17.01
\end{tabular} & $\begin{array}{l}25.13 \pm \\
7.61\end{array}$ & \begin{tabular}{|l}
$33.88 \pm$ \\
17.12 \\
\end{tabular} \\
\hline \multicolumn{6}{|l|}{ Gender } \\
\hline Male & \begin{tabular}{|l|}
24 \\
$(64.8 \%)$
\end{tabular} & \begin{tabular}{|l|l|}
13 \\
$(61.9 \%)$
\end{tabular} & \begin{tabular}{|l|l|}
12 \\
$(57.1 \%)$
\end{tabular} & \begin{tabular}{|l|}
27 \\
$(71.1 \%)$ \\
\end{tabular} & \begin{tabular}{|l|}
10 \\
$(58.8 \%)$ \\
\end{tabular} \\
\hline Female & $\begin{array}{l}13 \\
(35.2 \%)\end{array}$ & $8(38.1 \%)$ & $\begin{array}{l}9 \\
(42.9 \%)\end{array}$ & \begin{tabular}{|l}
11 \\
$(28.9 \%)$
\end{tabular} & $\begin{array}{l}7 \\
(41.2 \%) \\
\end{array}$ \\
\hline $\begin{array}{l}\text { Noncompacted myocardium } \\
(\mathrm{mm})\end{array}$ & $\begin{array}{l}12.59 \pm \\
1.15 \\
\end{array}$ & $\begin{array}{l}9.17 \pm \\
2.22\end{array}$ & $\begin{array}{l}9.19 \pm \\
8.80\end{array}$ & $\begin{array}{l}7.54 \pm \\
2.16 \\
\end{array}$ & $\begin{array}{l}10.65 \pm \\
3.1 \\
\end{array}$ \\
\hline $\begin{array}{l}\text { Compacted myocardium } \\
(\mathrm{mm})\end{array}$ & $\begin{array}{l}3.72 \pm \\
0.73\end{array}$ & $\begin{array}{l}6.01 \pm \\
1.84 \\
\end{array}$ & $\begin{array}{l}7.33 \pm \\
2.49\end{array}$ & $\begin{array}{l}6.48 \pm \\
2.26 \\
\end{array}$ & \begin{tabular}{|l|l|}
$5.05 \pm$ \\
1.18
\end{tabular} \\
\hline $\begin{array}{l}\text { Noncompacted-to- } \\
\text { compacted myocardium }\end{array}$ & $\begin{array}{l}3.42 \pm \\
0.69\end{array}$ & $\begin{array}{l}1.60 \pm \\
0.48\end{array}$ & $\begin{array}{l}1.32 \pm \\
0.53\end{array}$ & $\begin{array}{l}1.77 \pm \\
0.57\end{array}$ & $\begin{array}{l}2.11 \pm \\
0.48 \\
\end{array}$ \\
\hline Ejection fraction (\%) & $\begin{array}{l}48.45 \pm \\
9.69\end{array}$ & $\begin{array}{l}39.04 \pm \\
6.20 \\
\end{array}$ & $\begin{array}{l}70.09 \pm \\
5.56\end{array}$ & \begin{tabular}{|l}
$62.57 \pm$ \\
3.25 \\
\end{tabular} & \begin{tabular}{|l|}
$35.52 \pm$ \\
8.36
\end{tabular} \\
\hline \multicolumn{6}{|l|}{$\begin{array}{l}\text { Noncompacted-to- } \\
\text { compacted myocardium }>2.3\end{array}$} \\
\hline Yes & $\begin{array}{l}36 \\
(97.3 \%)\end{array}$ & $3(14.3 \%)$ & $\begin{array}{l}2 \\
(9.5 \%)\end{array}$ & \begin{tabular}{|l}
6 \\
$(15.8 \%)$
\end{tabular} & $\begin{array}{l}9 \\
(52.9 \%) \\
\end{array}$ \\
\hline No & $\begin{array}{l}1 \\
(2.7 \%)\end{array}$ & \begin{tabular}{|l}
18 \\
$(85.7 \%)$
\end{tabular} & \begin{tabular}{|l|l}
19 \\
$(90.5 \%)$
\end{tabular} & \begin{tabular}{|l}
32 \\
$(84.2 \%)$
\end{tabular} & \begin{tabular}{|l}
8 \\
$(47.1 \%)$ \\
\end{tabular} \\
\hline \multicolumn{6}{|l|}{$\begin{array}{l}\text { Noncompacted-to- } \\
\text { compacted myocardium } \\
>2.66\end{array}$} \\
\hline Yes & \begin{tabular}{|l}
34 \\
$(91.9 \%)$
\end{tabular} & 0 & 0 & \begin{tabular}{|l}
2 \\
$(94.7 \%)$
\end{tabular} & $\begin{array}{l}1 \\
(5.9 \%) \\
\end{array}$ \\
\hline No & \begin{tabular}{|l}
3 \\
$(8.1 \%)$ \\
\end{tabular} & $\begin{array}{l}21 \\
(100 \%) \\
\end{array}$ & $\begin{array}{l}21 \\
(100 \%)\end{array}$ & \begin{tabular}{|l}
36 \\
$(94.7 \%)$
\end{tabular} & \begin{tabular}{|l}
16 \\
$(94.1 \%)$ \\
\end{tabular} \\
\hline \multicolumn{6}{|l|}{$\begin{array}{l}\text { Noncompacted-to- } \\
\text { compacted myocardium }>2.8\end{array}$} \\
\hline Yes & $\begin{array}{l}30 \\
(81.1 \%)\end{array}$ & 0 & 0 & 0 & 0 \\
\hline No & \begin{tabular}{|l}
7( \\
$18.9 \%)$
\end{tabular} & $\begin{array}{l}21 \\
(100 \%)\end{array}$ & \begin{tabular}{|l|}
21 \\
$(100 \%)$
\end{tabular} & $\begin{array}{l}38 \\
(100 \%)\end{array}$ & $\begin{array}{l}1 \\
(100 \%)\end{array}$ \\
\hline
\end{tabular}

LVNC=Left ventricular noncompaction, HCM=Hypertrophic cardiomyopathy, DCM=Dilated cardiomyopathy

The mean noncompacted myocardium was $12.59 \pm 1.15 \mathrm{~mm}$, and the mean compacted myocardium was $3.72 \pm 0.73 \mathrm{~mm}$ in LVNC group. The mean $\mathrm{NC} / \mathrm{C}$ ratio was $3.42 \pm 0.69$ ranging from 2.27 to 5.43 in LVNC patients. We identified no correlation between the NC/C and EF in LVNC. The cut-off threshold value $>2.3$ was able to identify all but one LVNC patient (97.3\%). In this patient, the $\mathrm{NC} / \mathrm{C}$ ratio was 2.27 , which was close to the cutoff threshold value of $>2.3$. Nevertheless, the LVNC diagnosis in this particular patient was verified by other clinical and echocardiographic findings. On the other hand, 20 of 97 (20.6\%) patients in the control group had $\mathrm{NC} / \mathrm{C}$ ratio $>2.3$, which resulted in $79.4 \%$ specificity for the diagnosis of LVNC. Of these 20 patients, 2 had HCM, 3 had ischemic cardiomyopathy, 6 were healthy controls, and 9 were DCM patients. To identify a cut-off 
threshold value with higher specificity, receiver-operating curve (ROC) was implemented using the $\mathrm{NC} / \mathrm{C}$ ratio as a test and having LVNC as a state variable (Figure 4). Using the cut-off threshold value of $>2.66$ for the ratio for $\mathrm{NC} / \mathrm{C}$ layer as a semiquantitative criterion resulted in $91.9 \%$ sensitivity and $97 \%$ specificity and the cut-off threshold value of $>2.8$ resulted in $81 \%$ sensitivity and $100 \%$ specificity $(\mathrm{p}>0.05)$ (Table I).

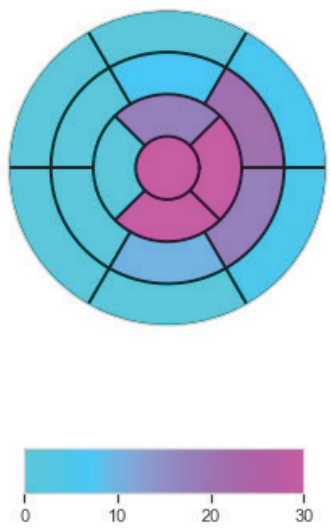

Figure 3. Bull-eye illustration shows the segments with $\mathrm{NC} / \mathrm{C}$ ratio > 2.3 in LVNC patients

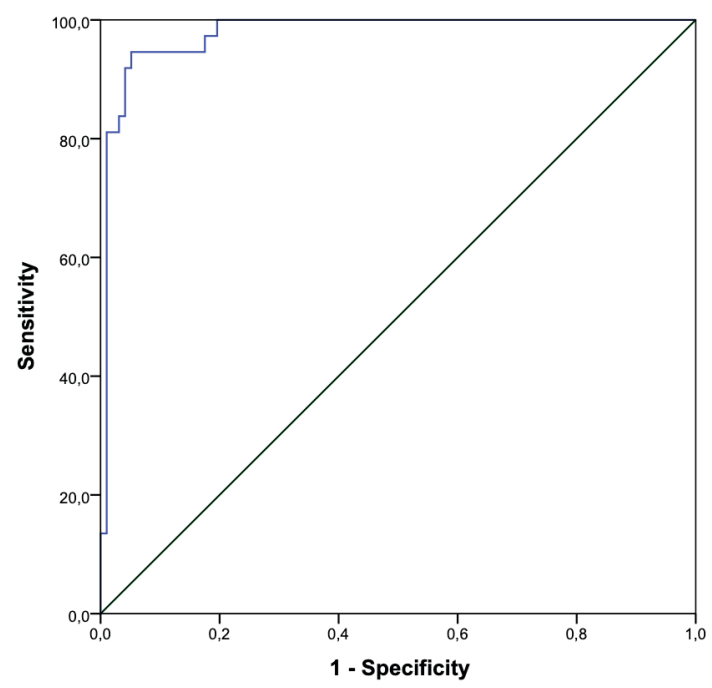

Figure 4. ROC curve analysis showing NC/C ratio $>2.3$ in predicting the presence of LVNC in the whole study cohort

Additionally, the control group was further subclassified according to their diagnosis as ischemic heart disease $(n=21)$, HCM $(n=21)$, healthy controls $(n=38)$, and DCM $(n=17)$ to explore the diagnostic performance of the cut-off threshold value $>2.3$ in discriminating LVNC patients comparing each subgroup. The subgroup analysis revealed that the cut-off threshold value of $>2.3$ had the worst diagnostic accuracy in discriminating LVNC patients from DCM patients $(81.4 \%)$ while had the best diagnostic accuracy in differing LVNC patients from HCM patients (94.8\%). The cut-off threshold value of $>2.3$ showed diagnostic accuracy of $90.6 \%$ with excellent sensitivity $(97.3 \%)$ despite relatively lower specificity (84.2\%) in discriminating LVNC patients from healthy controls. Table II depicts the detailed diagnostic metrices of the cut-off threshold value of $>2.3$ in discriminating LVNC patients from other subgroups.

Table II. The diagnostic performances of cut-off threshold value $>2.3$ in discriminating LVNC vs. each study subgroup.

\begin{tabular}{|l|l|l|l|l|l|}
\hline Conditions & Sensitivity & Specificity & NPV & PPV & $\begin{array}{l}\text { Diagnostic } \\
\text { accuracy }\end{array}$ \\
\hline $\begin{array}{l}\text { LVNC vs. ischemic } \\
\text { heart disease }\end{array}$ & $97.3 \%$ & $85.7 \%$ & $94.7 \%$ & $92.3 \%$ & $93.1 \%$ \\
\hline LVNC vs. HCM & $97.3 \%$ & $90.5 \%$ & $95 \%$ & $94.7 \%$ & $94.8 \%$ \\
\hline $\begin{array}{l}\text { LVNC vs. healthy } \\
\text { controls }\end{array}$ & $97.3 \%$ & $84.2 \%$ & $97 \%$ & $85.7 \%$ & $90.6 \%$ \\
\hline LVNC vs. DCM & $97.3 \%$ & $47.1 \%$ & $88.9 \%$ & $80 \%$ & $81.4 \%$ \\
\hline $\begin{array}{l}\text { LVNC vs. Whole } \\
\text { study cohort }\end{array}$ & $97.3 \%$ & $79.4 \%$ & $98.7 \%$ & $64.3 \%$ & $86.5 \%$ \\
\hline
\end{tabular}

LVNC= Left ventricular noncompaction, $\mathrm{HCM}=$ Hypertrophic cardiomyopathy, $\mathrm{DCM}=$ Dilated cardiomyopathy,

$\mathrm{NPV}=$ Negative predictive value, $\mathrm{PPV}=$ Positive predictive value

\section{DISCUSSION}

The findings of the present study indicated that utilizing NC/C wall threshold ratio $>2.3$ as recommended by Petersen et al. had excellent diagnostic sensitivity reaching up to $97.3 \%$, yet had rather a low specificity (79.4\%), hence, suggesting that it might lead to overdiagnosis. Notably, 6 of 38 healthy controls $(15.8 \%)$ in the present work had $\mathrm{NC} / \mathrm{C}$ wall ratio $>2.3$. We identified two different cut-off threshold values for $\mathrm{NC} / \mathrm{C}$ ratio for the diagnosis of LVNC, 2.66 and 2.8, which resulted in $91.9 \%$ sensitivity and $97 \%$ specificity and $81 \%$ sensitivity and $100 \%$ specificity, respectively.

In 2005, Petersen et al., introduced a cut-off value for the diagnosis of LVNC, NC/C wall ratio $>2.3$ by appraising 177 individuals with and without cardiac disease [12]. The cut-off value yielded excellent specificity (99\%) in their work, which was higher than the specificity value of $79.4 \%$ in the present work. Notably, we demonstrated higher sensitivity compared with their work ( $97.2 \%$ vs. $86 \%$ ). The mean NC/C myocardium ratio identified in their study was substantially lower than the present work $(3.0 \pm 1.5$ vs. $3.72 \pm 0.73)$. However, the study by Petersen et al., substantially suffered from the fact that their study cohort only had seven patients with a diagnosis of LVNC [12]. Notwithstanding this limitation, this cut-off value gained popularity in clinical applications while also had been subjected to considerable criticism by many authors. The study by Boban et al., supported the reliability of the initial criteria proposed by Petersen et al., [12, 18] and also suggested measuring noncompacted myocardium blood flow using T2 sequences and geometric eccentricity of the ventricle as supplementary diagnostic markers on CMRI for the diagnosis of LVNC. Boban 
et al., assessed the diagnostic value of $\mathrm{NC} / \mathrm{C}$ threshold ratio > 2.3 in 71 LVNC patients and 129 controls [18]. In their work, the cut-off threshold value revealed equal sensitivity (97.2\%) and comparably higher specificity (96.3\%) compared with the present study.

Contrarily, the authors of The Multi-Ethnic Study of Atherosclerosis (MESA) found that 140 of 323 healthy individuals (43\%) had NC/C wall threshold ratio $>2.3$ at least in one segment of the myocardium, and questioned the reliability of the cut-off value [13]. The authors suggested the re-evaluation of the criteria [13]. A further study by the MESA investigators showed that using $\mathrm{NC} / \mathrm{C}$ threshold ratio $>2.3$ led to an incorrect diagnosis of LVNC in 706 of 2742 (25.7\%) participants without any known cardiac disease [14]. Furthermore, only in the number of negligible patients, noncompacted myocardium headed to changes in left ventricular parameters over ten years $[13,14]$. Fazio et al., also questioned the over sensitivity of the $\mathrm{NC} / \mathrm{C}$ wall threshold ratio and proposed to use $>2.5$ cutoff threshold value for the diagnosis of LVNC on CMRI [19]. Grofthoff et al., explored the reliability of the cut-off threshold value of 2.3 in their study that consisted of 12 patients with LVNC and 24 controls [15]. The authors demonstrated that NC/C ratio $>2.3$ had $100 \%$ sensitivity while $80 \%$ specificity, which was comparable with our findings [15]. The authors demonstrated that using the NC/C threshold ratio $>3$ yielded $100 \%$ sensitivity and $93 \%$ specificity [15]. In the present work, the determined cut-off threshold value, NC/C ratio > 2.66, resulted in $91.9 \%$ sensitivity and $97 \%$ specificity, which had higher specificity despite lower sensitivity than their study.

In line with the aforementioned works, the findings of the present work highlighted that using NC/C wall threshold ratio $>2.3$ might lead to overdiagnosis of LVNC in an important amount of patients. The misdiagnosis of LVNC might cause severe and unnecessary burdens for the psychical and mental well-being of the individuals $[20,21]$. We suggest that NC/C wall threshold ratio $>2.3$ should be used only in patients with a high clinical suspicion of LVNC, and in patients without any specific symptoms, echocardiographic or electrocardiographic findings suggesting LVNC, and the clinicians should keep in mind that using $\mathrm{NC} / \mathrm{C}$ wall threshold ratio $>2.3$ for the diagnosis of LVNC might result in overdiagnosis. In such instances, other proposed methods such as measuring trabeculated ventricular mass, fractal analyses, or higher cut-off values, which yielded higher specificity as proposed in the present work might be used $[15,22,23]$. Furthermore, the number of the segments with NC/C wall threshold ratio > 2.3 in LVNC patients was substantially higher than the control group in the current work. Notably, no patients in control group had 4 or more myocardial segments with $\mathrm{NC} / \mathrm{C}$ wall ratio $>2.3$, and only 1 patient had 3 segments with $\mathrm{NC} / \mathrm{C}$ wall ratio $>2.3$. All other participants in the control group had only 1 or 2 segments with $\mathrm{NC} / \mathrm{C}$ wall ratio $>$ 2.3. Contrarily, with no LVNC patients had only 1 segment $\mathrm{NC} / \mathrm{C}$ wall ratio $>2.3$ and approximately $86 \%$ of LVNC patients meeting the diagnostic CMRI criteria had 3 or more segments with $\mathrm{NC} / \mathrm{C}$ wall ratio $>2.3$. Hence, we suggest that the number of the segments with $\mathrm{NC} / \mathrm{C}$ wall ratio $>2.3$ might be also beneficial in identifying LVNC. Nevertheless, we acknowledged that there is a pressing need to address the issue of overdiagnosis of LVNC by CMRI, and besides criteria relying solely on imaging modalities, diagnostic workflow combined with clinical and imaging data as proposed by several authors might also be beneficial to reduce the number of incorrect diagnoses.

Finally, some important limitations of this present work need to be viewed. First, and foremost, the retrospective nature of the study inherently limits the generalizability of our results. Second, there was a selection bias since the study and control cohort was derived from a tertiary referral center; hence, the cohort in the study might have differed from the general population in several aspects. Third, we had a relatively small number of patients with LVNC given to scarcity of the disease. Nevertheless, our sample size was higher than those of several similar works $[12,15,19]$. Fourth, we did not assess inter-observer variability of NC/C ratio measurements; however, previous studies demonstrated that this measurement technique had a good inter-observer reliability [16]. Finally, we did not investigate several other quantitative methods proposed for the diagnosis of LVNC [15,22-24].

In conclusion, using $\mathrm{NC} / \mathrm{C}$ wall threshold ratio $>2.3$ for the diagnosis of LVNC had excellent sensitivity, yet rather a low specificity. Our findings indicated that NC/C threshold ratio $>2.3$ might lead to overdiagnosis of LVNC in the healthy population. Furthermore, using NC/C threshold ratio $>2.3$ might also lead to misdiagnosis of other cardiomyopathies, particularly DCM, as LVNC. Therefore, we suggest that using higher NC/C cut-off threshold values or integrating other measures such as measuring trabeculated ventricular mass, fractal analyses, or taking the number of the segments with $\mathrm{NC} / \mathrm{C}$ wall ratio $>2.3$ might be implemented in daily clinical practice to avoid incorrect diagnoses.

\section{Conflict of interest statement: None}

Ethical Statement: All procedures performed in studies involving human participants were in accordance with the ethical standards of the institutional and/or national research committee and with the 1964 Helsinki declaration and its later amendments or comparable ethical standards. Institutional Ethics Committee approval was obtained.

Funding statement: This research did not receive any specific grant from funding agencies in the public, commercial, or notfor-profit sectors.

\section{REFERENCES}

[1] Ritter M, Oechslin E, Sutsch G, Attenhofer C, Schneider J, Jenni R. Isolated noncompaction of the myocardium in adults. Mayo Clin Proc 1997; 72:26-31. doi: 10.1016/j.jacc.2015.06.017

[2] Oechslin EN, Attenhofer Jost CH, Rojas JR, Kaufmann PA, Jenni R. Long-term follow-up of 34 adults with isolated left ventricular noncompaction: a distinct cardiomyopathy with poor prognosis. J Am Coll Cardiol 2000; 36:493-500. doi: 10.1016/S0735-1097(00)00755-5 
[3] Oechslin E, Jenni R. Left ventricular non-compaction revisited: a distinct phenotype with genetic heterogeneity? Eur Heart J 2011; 32:1446-56. doi:10.1093/eurheartj/ehq508

[4] Elliott P, Andersson B, Arbustini E, et al. Classification of the cardiomyopathies: a position statement from the European Society of Cardiology Working Group on Myocardial and Pericardial Diseases. Eur Heart J 2008; 29:270-6. doi: 10.1093/ eurheartj/ehm342

[5] Maron BJ, Towbin JA, Thiene G, et al. Contemporary definitions and classification of the cardiomyopathies: an American Heart Association Scientific Statement from the Council on Clinical Cardiology, Heart Failure and Transplantation Committee; Quality of Care and Outcomes Research and Functional Genomics and Translational Biology Interdisciplinary Working Groups; and Council on Epidemiology and Prevention. Circulation 2006; 113:1807-16. doi: 10.1161/CIRCULATIONAHA.106.174287

[6] Ichida F, Tsubata S, Bowles KR, et al. Novel gene mutations in patients with LV noncompaction or Barth syndrome. Circulation 2001; 103:1256-63. https://doi.org/10.1161/01. cir.103.9.1256

[7] Klaassen S, Probst S, Oechslin E, et al. Mutations in sarco mere protein genes in LV noncompaction. Circulation 2008; 117:2893-2901. doi: 10.1161/CIRCGENETICS.109.903898

[8] Sasse-Klaassen S, Gerull B, Oechslin E, Jenni R, Thierfelder $\mathrm{L}$. Isolated noncompaction of the LV myocardium in the adult is an autosomal dominant disorder in the majority of patients. Am J Med Genet A 2003; 119:162-7. doi: 10.1002/ ajmg.a.20075

[9] Jenni R, Oechslin E, Schneider J, Attenhofer Jost CH, Kaufmann PA. Echocardiographic and pathoanatomical characteristics of isolated LV non-compaction: a step towards classification as a distinct cardiomyopathy. Heart 2001; 86:666-71. doi: 10.1136/heart.86.6.666

[10] Oechslin EN, Jost CHA, Rojas JR, Kaufmann PA, Jenni R, Long-term follow-up of 34 adults with isolated left ventricular noncompaction: a distinct cardiomyopathy with poor prognosis. J Am Coll Cardiol 2000; 36:493-500. doi:10.1016/ s0735-1097(00)00755-5

[11] Martin M, Barriales V, Corros C, Santamaria E. Usefulness of cardiac magnetic resonance imaging in LV non-compaction cardiomyopathy. Eur J Heart Fail 2011; 13:177-85. doi: 10.1093/eurjhf/hfr028

[12] Petersen SE, Selvanayagam JB, Wiesmann F, et al. LV noncompaction: insights from cardiovascular magnetic resonance imaging. J Am Coll Cardiol 2005; 46:101-5. doi: 10.1016/j. jacc.2005.03.045

[13] Kawel N, Nacif M, Arai AE, et al. Trabeculated (noncompacted) and compact myocardium in adults: the multi-ethnic study of atherosclerosis. Circ Cardiovasc Imaging 2012; 5:357-66. https://doi.org/10.1161/CIRCIMAGING.111.971713

[14] Tizon-Marcos H, de la Paz RM, Pibarot P, et al. Characteristics of trabeculated myocardium burden in young and apparently healthy adults. Am J Cardiol. 2014; 114:1094-9. doi: 10.1016/j. amjcard.2014.07.025

[15] Grothoff M, Pachowsky M, Hoffmann J, et al. Value of cardiovascular MR in diagnosing left ventricular noncompaction cardiomyopathy and in discriminating between other cardiomyopathies. Eur Radiol 2012; 22:2699-2709. doi:10.1007/s00330.012.2554-7

[16] Zuccarino F, Vollmer I, Sanchez G, Navallas M, Pugliese F, Gayete A. Left ventricular noncompaction: imaging findings and diagnostic criteria. AJR Am J Roentgenol 2015; 204:51930. doi: 10.2214/AJR.13.12326

[17] Cerqueira MD, Weissman NJ, Dilsizian V, et al. Standardized myocardial segmentation and nomenclature for tomographic imaging of the heart: a statement for healthcare professionals from the Cardiac Imaging Committee of the Council on Clinical Cardiology of the American Heart Association. Circulation 2002; 105:539-42. doi: 10.1161/hc0402.102975

[18] Boban M, Pesa V, Beck N, et al. Supplementary diagnostic landmarks of left ventricular non-compaction on magnetic resonance imaging. Yonsei Med J 2018; 59:63-71. doi: 10.3349/ ymj.2018.59.1.63

[19] Fazio G, Novo G, D’angelo L, Visconti C, et al. Magnetic resonance in isolated noncompaction of the ventricular myocardium. Int J Cardiol Heart Vasc 2010; 140:367-9. doi: 10.1016/j.ijcard.2008.11.080

[20] Chrissoheris MP, Ali R, Vivas Y, Marieb M, Protopapas Z. Isolated noncompaction of the ventricular myocardium: contemporary diagnosis and Management. Clin Cardiol 2007; 30:156-60. doi: 10.1002/clc.20004

[21] Murphy RT, Thaman R, Blanes JG, et al. Natural history and familial characteristics of isolated left ventricular noncompaction. Eur Heart J 2005; 26:187-92. doi: 10.1093/ eurheartj/ehi025

[22] Choi Y, Kim SM, Lee SC, Chang, SA, Jang,SY, Choe YH. Quantification of left ventricular trabeculae using cardiovascular magnetic resonance for the diagnosis of left ventricular non-compaction: evaluation of trabecular volume and refined semi-quantitative criteria. J Cardiovasc Magn Reson 2016; 18:24. doi: 10.1186/s12968.016.0245-2

[23] Captur G, Muthurangu V, Cook C, et al. Quantification of left ventricular trabeculae using fractal analysis. J Cardiovasc Magn Reson 2013; 15:36. doi: 10.1186/1532-429X-15-36

[24] Gati S, Rajani R, Carr-White GS, Chambers JB. Adult left ventricular noncompaction: reappraisal of current diagnostic imaging modalities. JACC: Cardiovascular Imaging 2014; 7:1266-75. doi: 10.1016/j.jcmg.2014.09.005 